\title{
Superconductivity with High Upper Critical Field in the Cubic Centrosymmetric $\eta$-Carbide $\mathrm{Nb}_{4} \mathrm{Rh}_{2} \mathrm{C}_{1-\delta}$
}

\author{
KeYuan Ma,${ }^{\dagger}$ Karolina Gornicka, ${ }^{\ddagger}$ Robin Lefèvre, ${ }^{\dagger}$ Yikai Yang,,$~ " H e n r i k$ Rønnow, ${ }^{\natural}$ \\ Harald O. Jeschke, ${ }^{\S}$ Tomasz Klimczuk, ${ }^{\ddagger}$ Fabian O. von Rohr ${ }^{\dagger} *$ \\ $\dagger$ Department of Chemistry, University of Zurich, CH-8057 Zurich, Switzerland \\ $\$$ Faculty of Applied Physics and Mathematics, Gdansk University of Technology, \\ Gdansk 80-233, Poland \\ 9 Institute of Physics, Ecole Polytechnique Fédérale de Lausanne (EPFL), CH-1015 \\ Lausanne, Switzerland \\ $\S$ Research Institute for Interdisciplinary Science, Okayama University, Okayama 700- \\ 8530, Japan
}

* To whom correspondence should be addressed. E-mail: fabian.vonrohr@chem.uzh.ch 


\section{Synthesis of phase pure sample}

In order to obtain phase pure samples, we synthesized a series of samples with varying compositions (see Sfig. 1-2). It was found that the development of optimized synthesis conditions was crucial for the realization of phase pure samples. Pure sample is obtained when the carbon is set to be 0.7 , more or less carbon will lead to the formation of other impurities, indicating carbon has a solubility in filling up the interstitial positions to stabilize the $\eta$-carbide crystal structure. Efforts attempting to replace carbon with nitrogen or oxygen were failed. From the composition varying synthesis, we find carbon is the only interstitial atoms that can stabilize $\mathrm{Nb}_{4} \mathrm{Rh}_{2} \mathrm{C}_{1-\delta}$ in the $\eta$-carbide crystal structure, and proper carbon deficiency is necessary to obtain phase pure samples. 

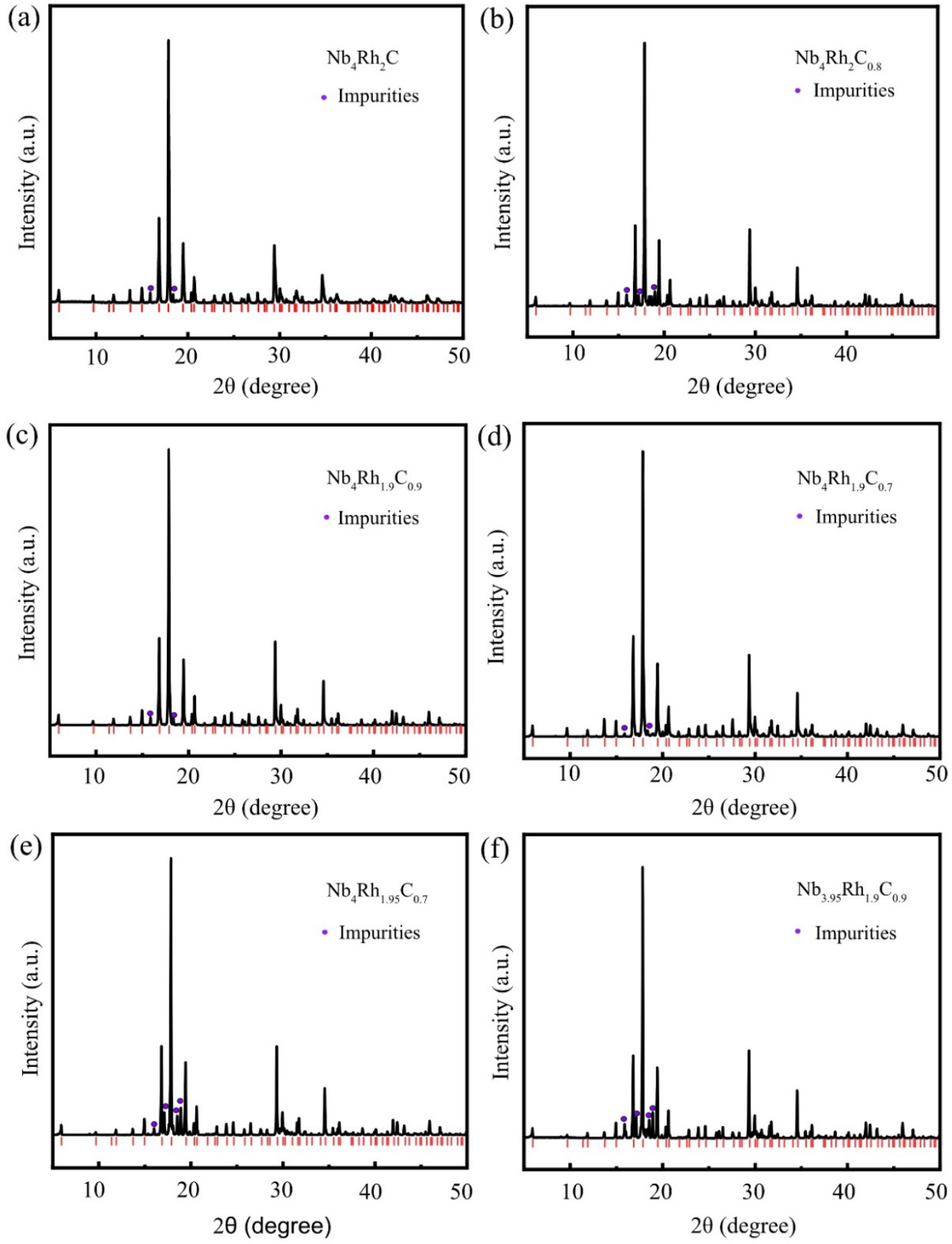

S-Figure 1. PXRD patterns of the products with varying starting chemical compositions 

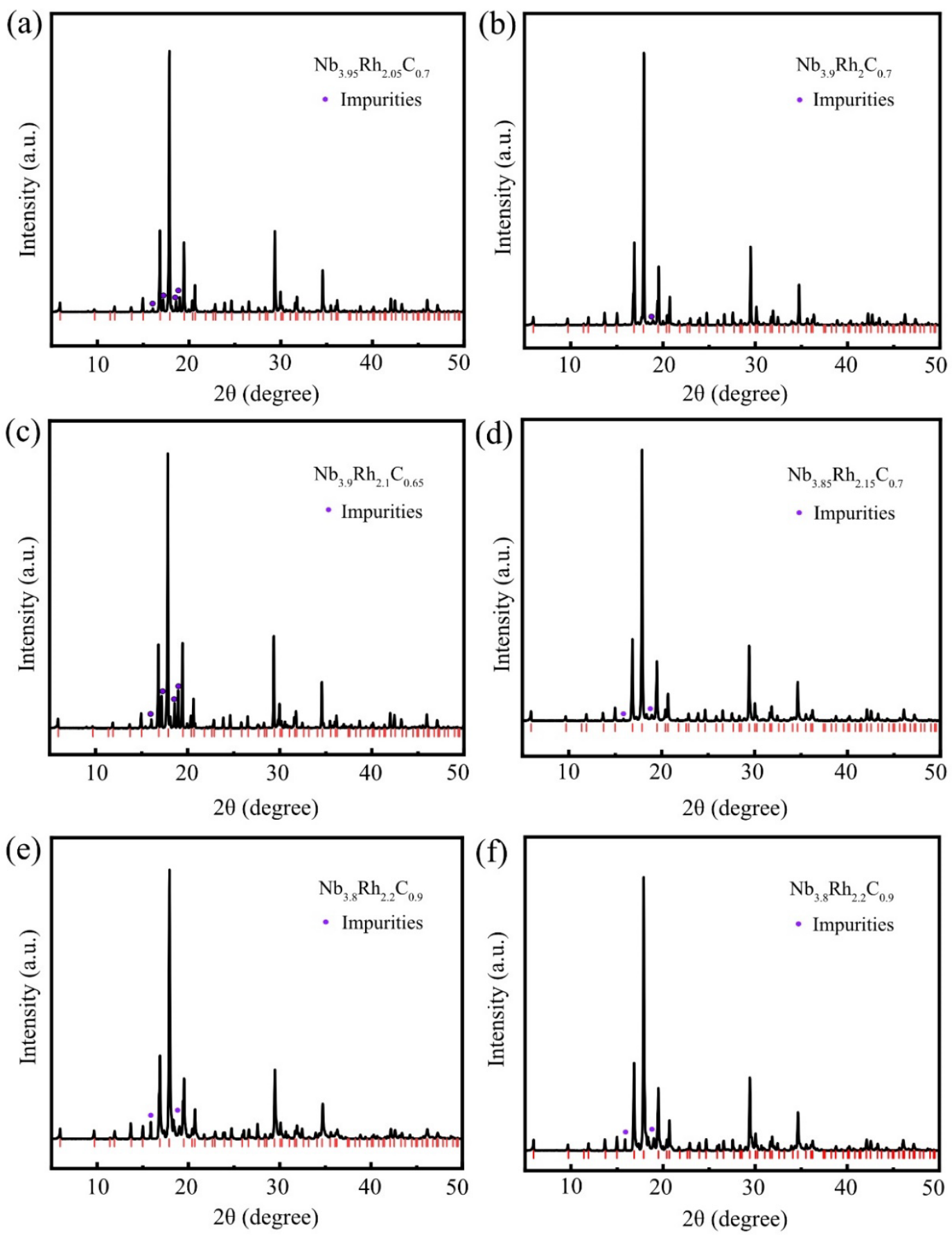

S-Figure 2. PXRD patterns of the products with varying starting chemical compositions 

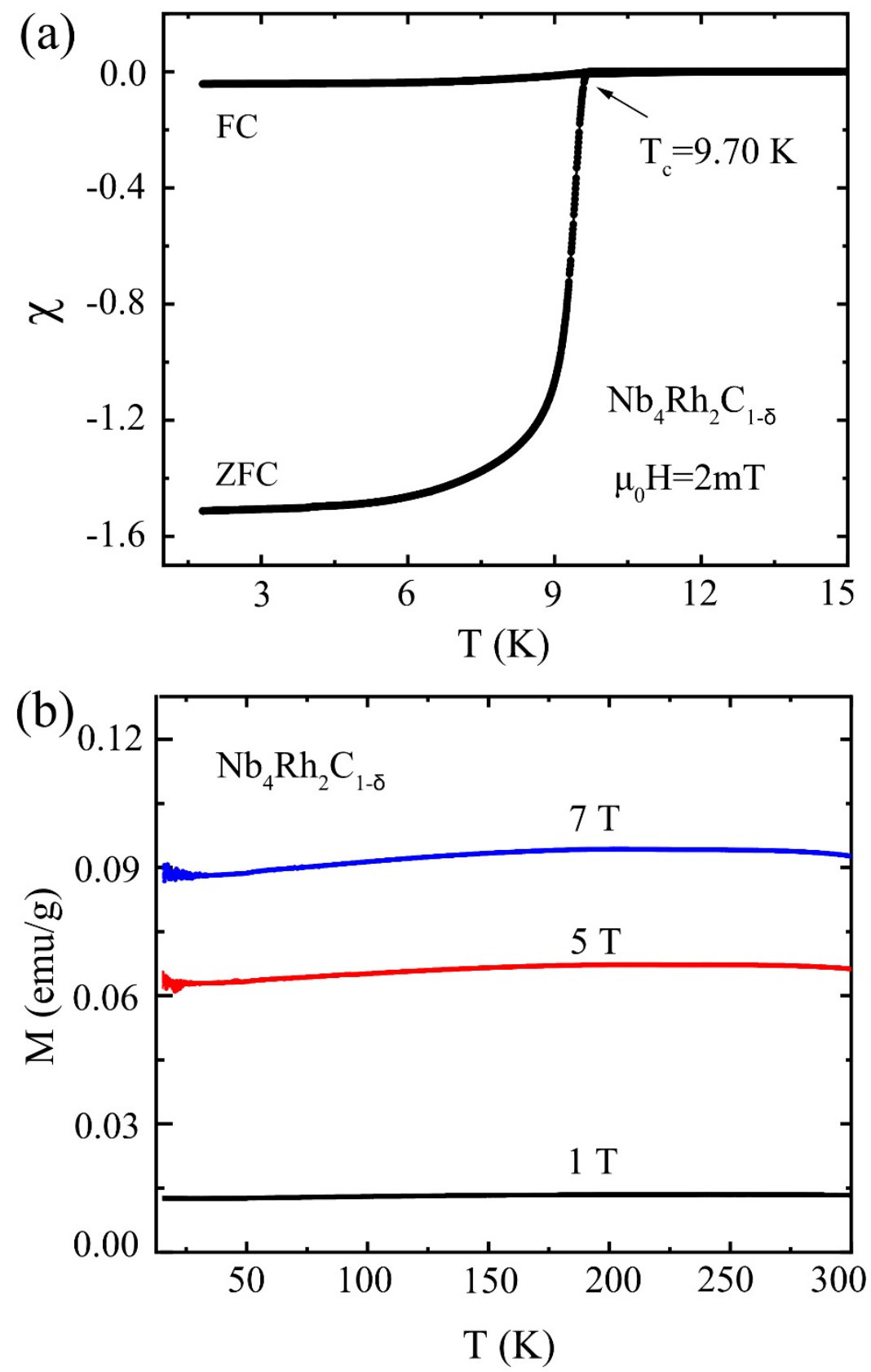

S-Figure 3. (a) Temperature dependence of the magnetic susceptibility in zero field cooled (ZFC) and field cooled (FC) modes for $\mathrm{Nb}_{4} \mathrm{Rh}_{2} \mathrm{C}_{1-\delta}$ and (b) normal state magnetization of $\mathrm{Nb}_{4} \mathrm{Rh}_{2} \mathrm{C}_{1-\delta}$ in a field of $\mu_{0} \mathrm{H}=1 \mathrm{~T}, 5 \mathrm{~T}$ and $7 \mathrm{~T}$ between 10 to $300 \mathrm{~K}$. 


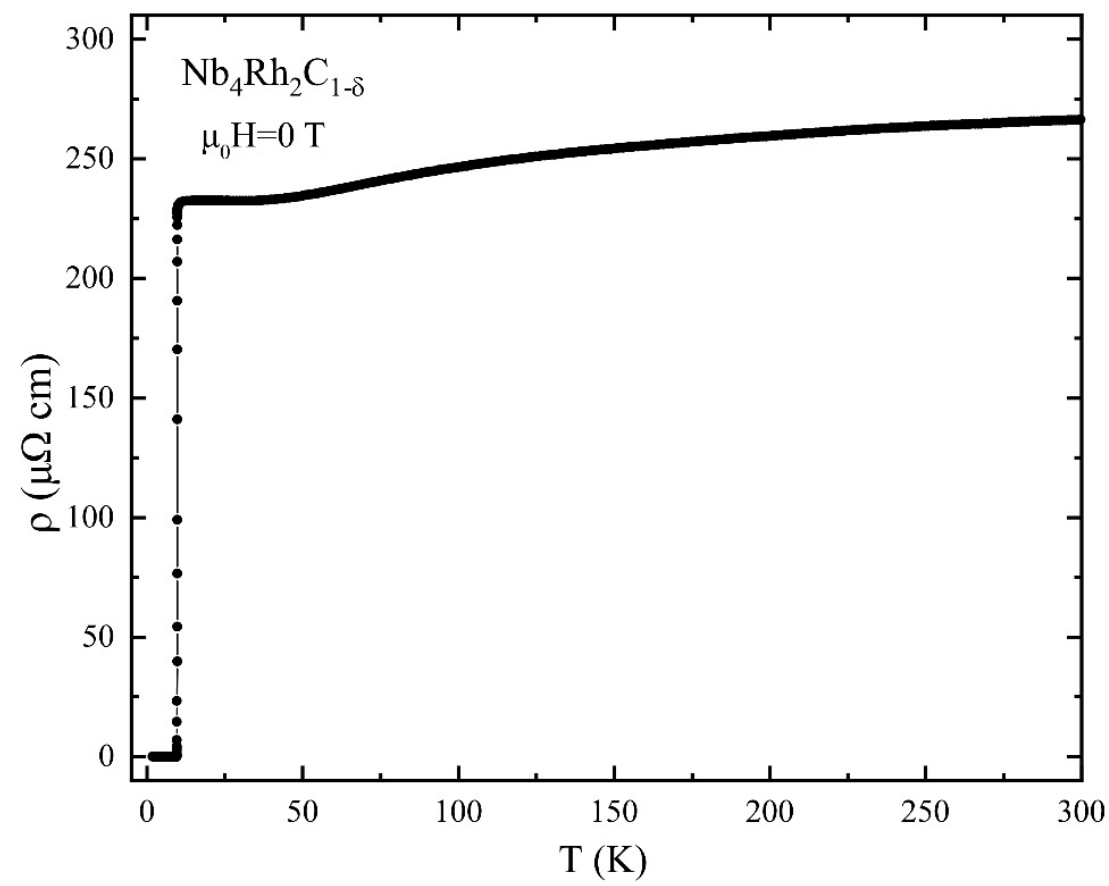

S-Figure 4. Resistivity of $\mathrm{Nb}_{4} \mathrm{Rh}_{2} \mathrm{C}_{1-\delta}$ in a field of $\mu_{0} \mathrm{H}=0 \mathrm{~T}$ between 2 to $300 \mathrm{~K}$ 

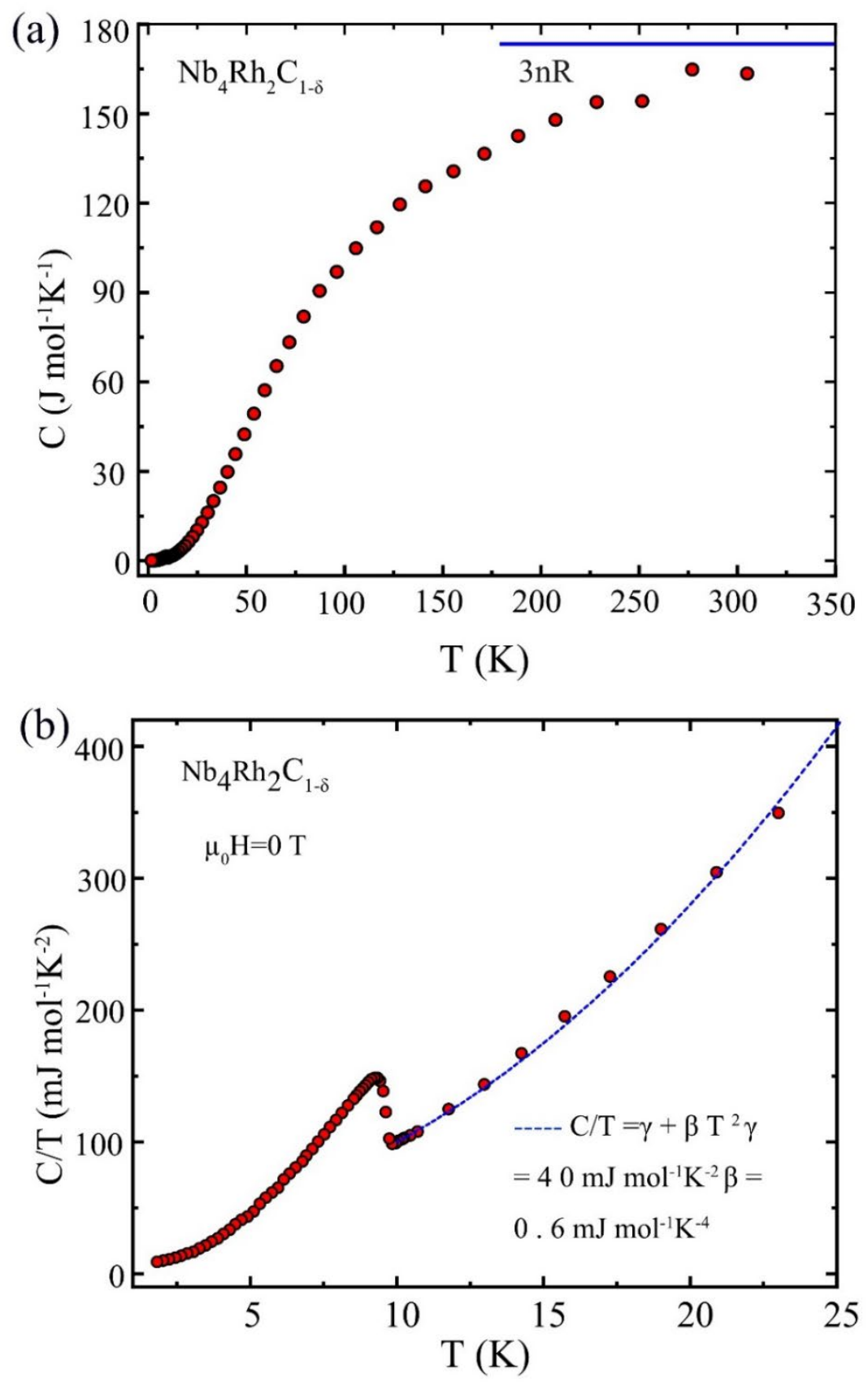

S-Figure 5. Temperature-dependent specific heat capacities $\mathrm{C}(\mathrm{T})$ of $\mathrm{Nb}_{4} \mathrm{Rh}_{2} \mathrm{C}_{1-\delta}$ between $=2 \mathrm{~K}$ to $320 \mathrm{~K}$. The data between $10 \mathrm{~K}$ to $25 \mathrm{~K}$ is plotted in a $\mathrm{C} / \mathrm{T}$ vs. T representation. The dotted line corresponds to a fit of the normal state specific heat capacities, according to equation $\mathrm{C} / \mathrm{T}=\left(\mathrm{C}_{\mathrm{el}}+\right.$ $\left.\mathrm{C}_{\mathrm{ph}}\right) / \mathrm{T}=\gamma+\beta \mathrm{T}^{2}$. 
Here, the upper critical field $\mathrm{H}_{\mathrm{C2}}(0)$ was determined using the Ginzburg-Landau (GL) model, with $\mathrm{t}=\mathrm{T} / \mathrm{T}_{\mathrm{c}}$ being the reduced temperature:

$$
H_{c 2}(T)=H_{c 2}(0) \frac{1-t^{2}}{1+t^{2}}
$$

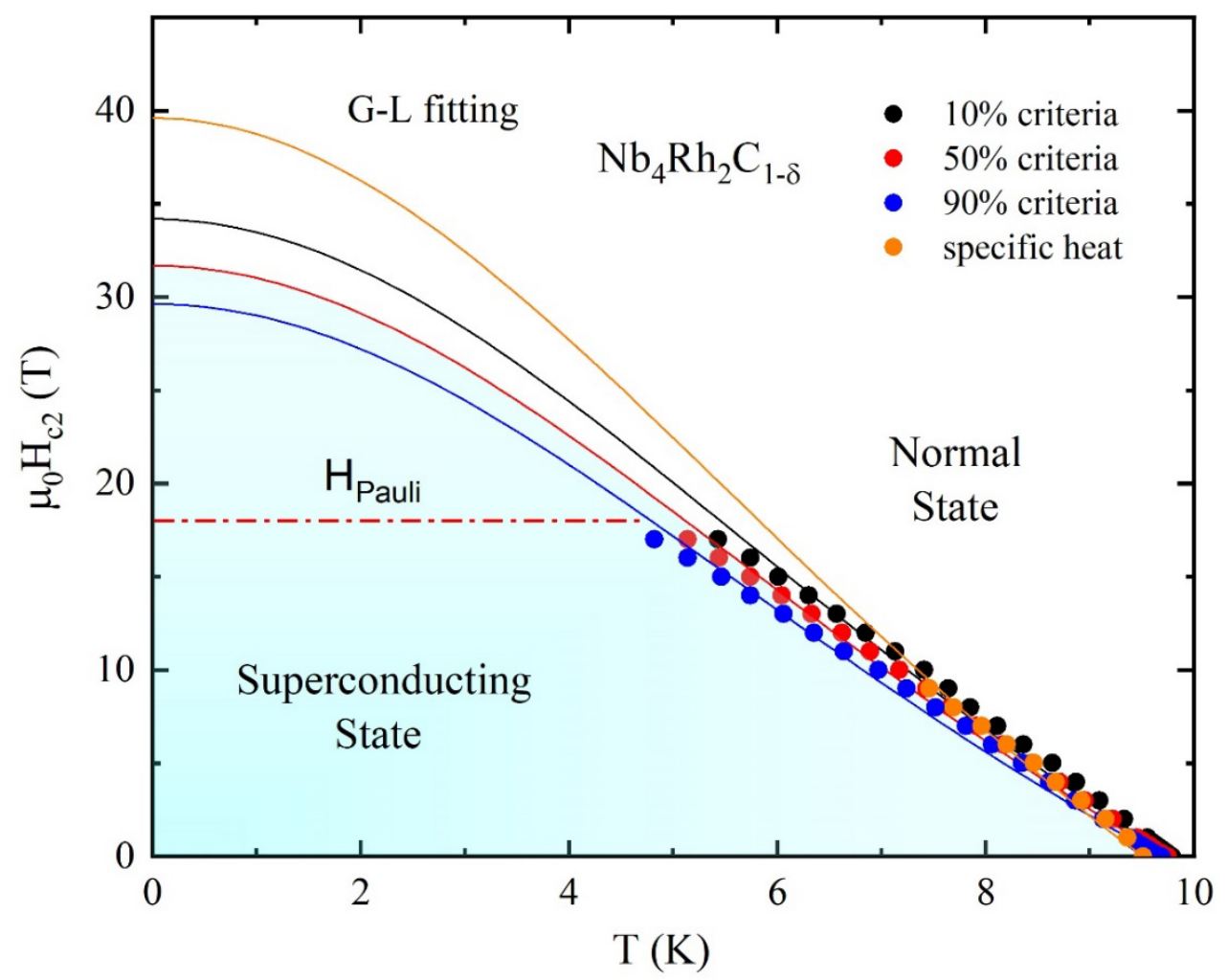

S-Figure 6. Upper critical fields of $\mathrm{Nb}_{4} \mathrm{Rh}_{2} \mathrm{C}_{1-\delta}$ determined by the $10 \%, 50 \%, 90 \%$ criterion with magnetic field up to $17 \mathrm{~T}$ and specific heat with Ginzburg-Landau formalism. 

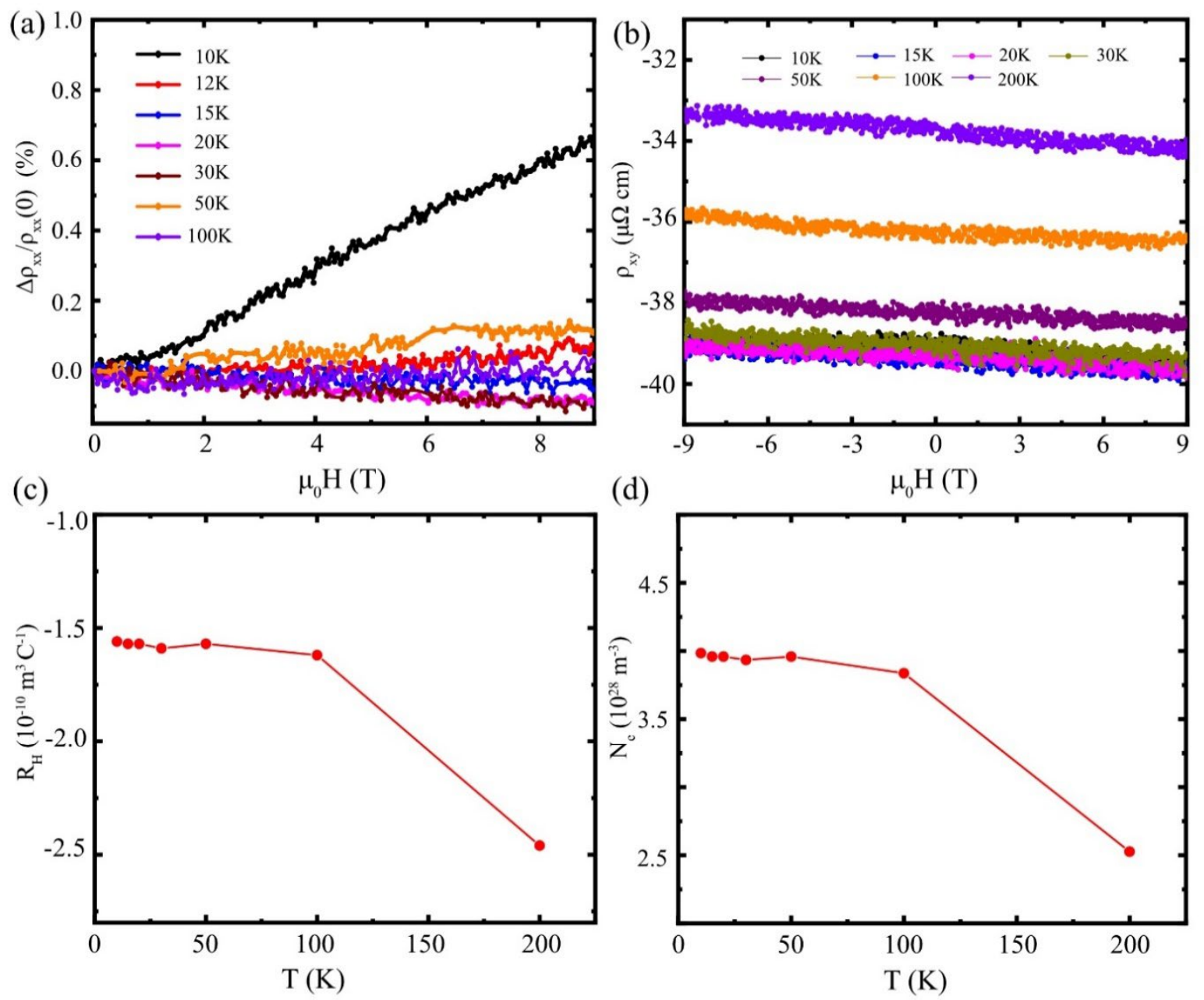

S-Figure 7. (a) Temperature-dependent magnetoresistance, (b) Magnetic field dependence of the transverse resistivity $\rho_{x y}$ at different temperatures, (c) Temperature dependence of Hall coefficient $\mathrm{R}_{\mathrm{H}}$, and (d) Temperature dependence of Carrier densities in $\mathrm{Nb}_{4} \mathrm{Rh}_{2} \mathrm{C}_{1-\delta}$. 


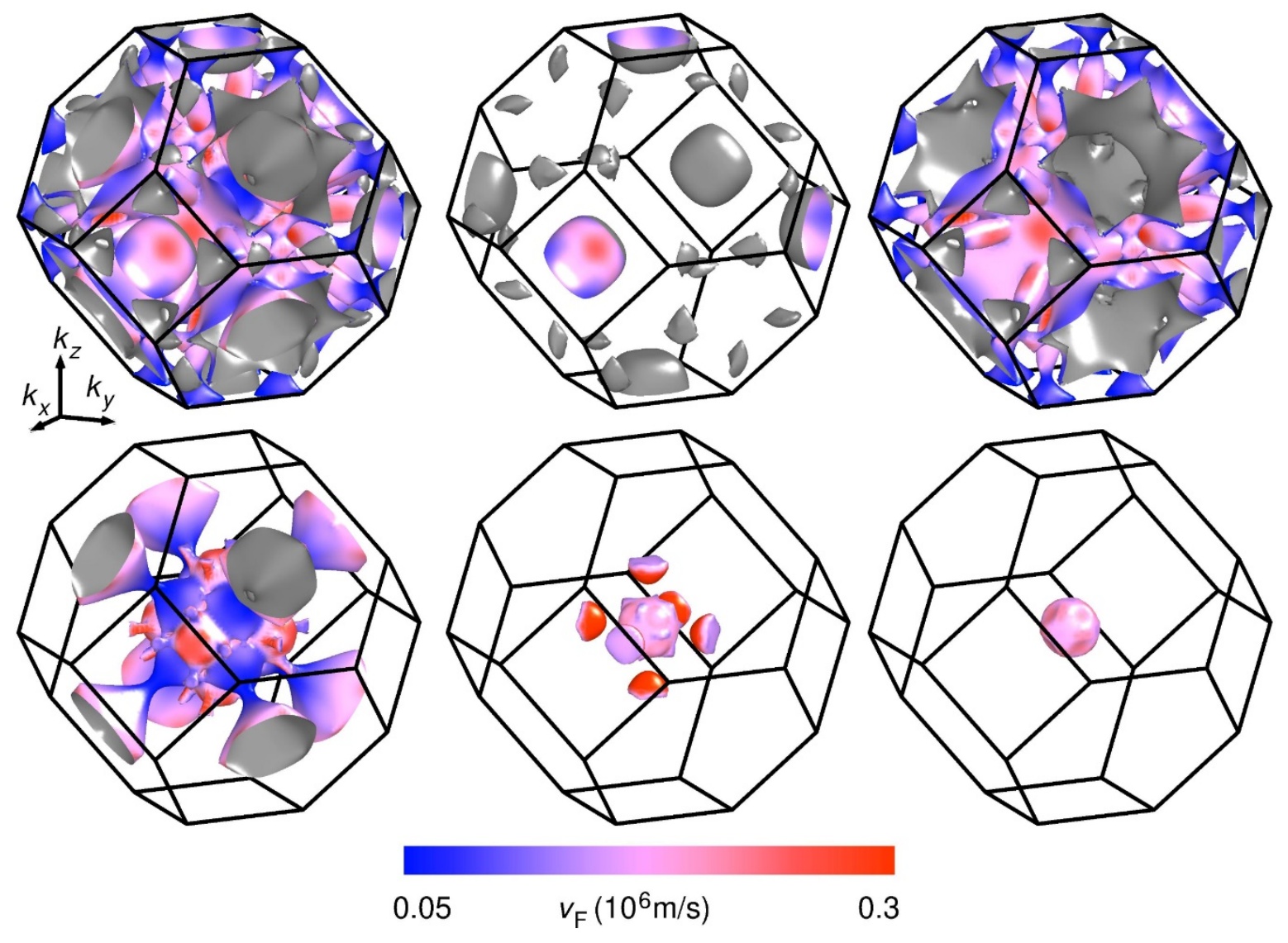

S-Figure 8. Calculated Fermi surface for $\mathrm{Nb}_{4} \mathrm{Rh}_{2} \mathrm{C}_{1-\delta}$ with $\delta=0.3$ 

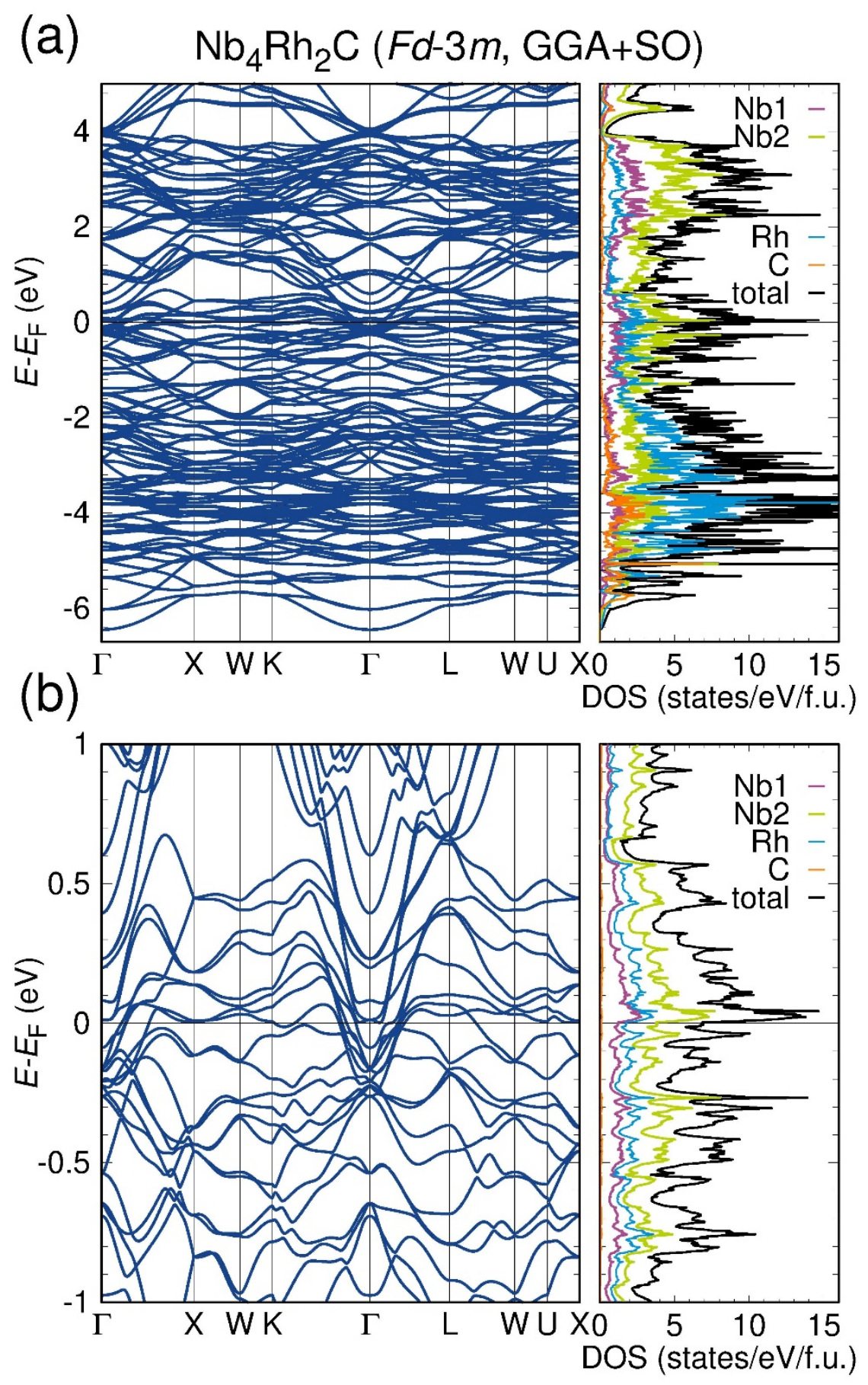

S-Figure 9. GGA+SO calculation. 


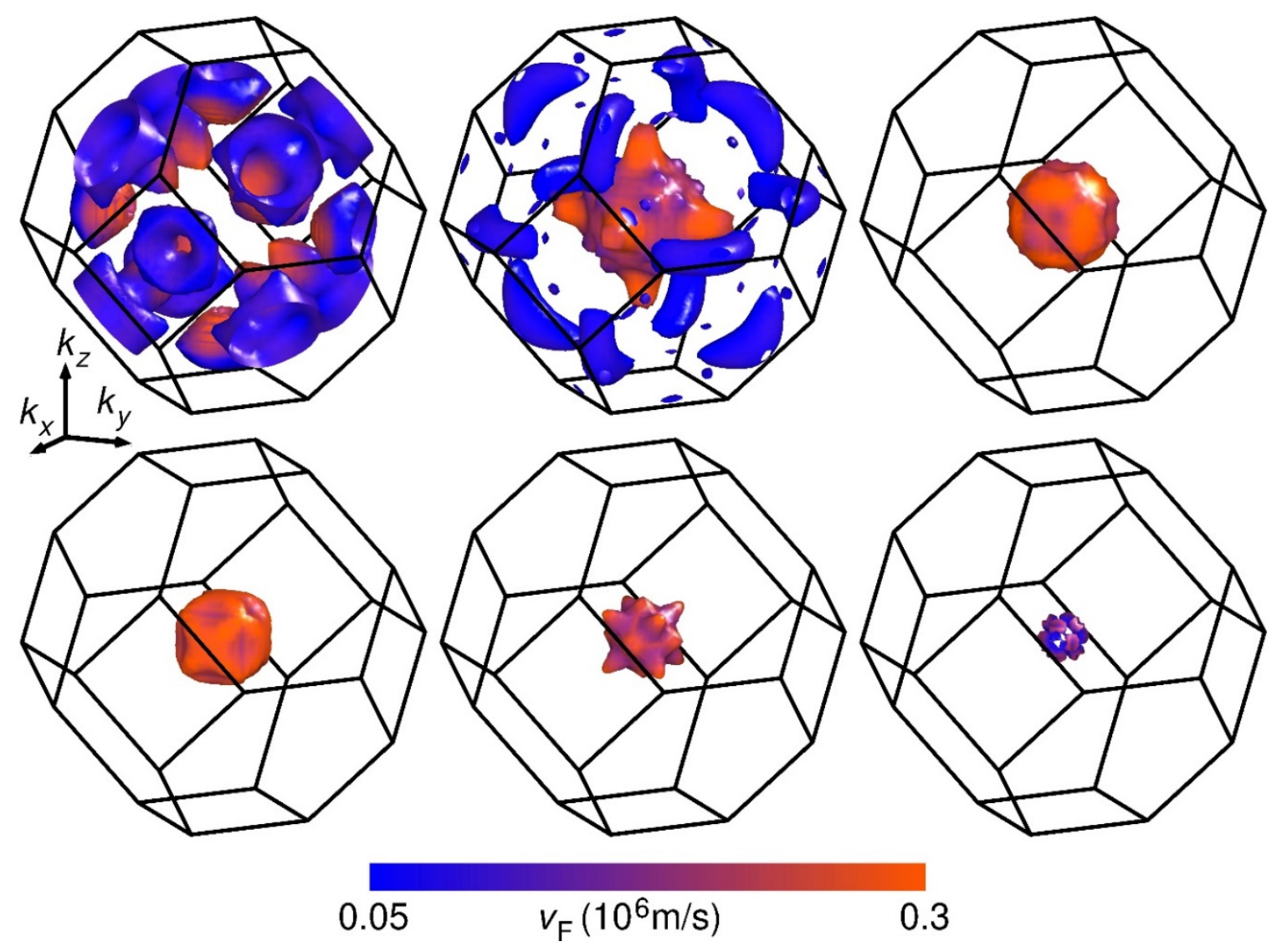

S-Figure 10. Calculated Fermi surface for $\mathrm{Nb}_{4} \mathrm{Rh}_{2} \mathrm{C}_{1-\delta}$ with $\delta=0$ 